Access to Opportunities for Bilingualism for Individuals with Developmental

Disabilities: Key Informant Interviews

Julia Scherba de Valenzuelaa, Elizabeth Kay-Raining Bird, Karisa Parkington, Pat Mirenda, Kate Cain, Andrea A.N. MacLeod, Eliane Segers

Journal of Communication Disorders 63 (2016) 32-46

http://dx.doi.org/10.1016/j.jcomdis.2016.05.005 


\begin{abstract}
The purpose of this article is to describe the results of a thematic analysis of 79 semi-structured interviews collected at six research sites in four countries in relation to the inclusion and exclusion of students with developmental disabilities (DD) in and from special education and bilingual opportunities. The participants were individuals with expertise either in special needs and/or language education to support bilingualism (e.g., second language (L2) instruction), who served as key informants about service delivery and/or policy in these areas. Six themes emerged as salient during the analysis: we include all kids, special needs drives it, time/scheduling conflicts, IEP/IPP/statement drives it, it's up to the parents, and service availability. The results suggested that access to language programs and services is limited for children with DD, even though participants at all sites reported adherence to a philosophy of inclusion. A priority on special education services over language services was identified, as well as barriers to providing children with DD access to programs and services to support bilingual development. Some of these barriers included time and scheduling conflicts and limited service availability. Additionally, the role of parents in decision making was affirmed, although, in contrast to special education services, decision-making about participation or exemption from language programs was typically left up to the parents. Overall, the results suggest a need for greater attention to providing supports for both first (L1) and L2 language development for bilingual children with DD and greater access to available language programs.
\end{abstract}




\section{Access to Opportunities for Bilingualism for Individuals with Developmental Disabilities: Key Informant Interviews}

\section{Introduction}

Children become bilingual in a number of ways and for a number of reasons. Some learn both languages at home from a very early age (simultaneous bilinguals). Others learn one language initially at home and then are exposed to an L2, often when they enter school (sequential bilinguals). For individuals who enter an educational system where the language of instruction is different from their home language, learning the L2 is a functional requirement of the educational setting. This is the case for sequential bilinguals from language minority backgrounds who enter a school where the language of instruction is the majority language (e.g., English schooling in the U.S.). It is also the case for children who speak the majority language at home but enter a school in which the language of instruction is a minority language (e.g., French Immersion in Canada). Children who speak one language at home and another at school may receive support to learn the language of instruction in school through, for example, English/Dutch as a Second Language (ESL/DSL) programs or use of bilingual education assistants who support the child in the classroom. Alternatively, development of both languages of a child may be facilitated through bilingual education programs. In this study, we investigated whether children with DD had access to and participated in the language education programs and supports available in their communities and, if they did not, the reasons for this. To study this, we conducted interviews with key informants at six sites within four countries (Canada, U.S., UK, and the Netherlands), in order to incorporate multiple perspectives. In order to capture a wide lens on disability, we defined DD broadly, including students with intellectual disability, multiple disabilities, and autism spectrum disorders, as well as specific language impairment. 


\subsection{Bilingualism and DD}

Until fairly recently, there was little research on the potential of individuals with DD to learn more than one language. Early research (e.g., Greenlee, 1981; Vallar \& Papagno, 1993; Woll \& Grove, 1996) suggested that children with DD were capable of bilingualism, but it has only been in the last 15 years that a significant amount of work has been carried out in this area. Collectively, the evidence demonstrates that individuals with DD can, indeed, develop more than one language in a manner similar to monolingual peers with the same disability and without detrimental effects on their language or cognitive development (see Kay-Raining Bird et al., this issue; Kohnert \& Medina, 2009; Paradis, Genesee, \& Crago, 2011 for reviews).

A number of studies have compared the effectiveness of intervention provided in the home or school languages. Some of these have studied students with autism spectrum disorders (Dalmau et al., 2011; Lang et al., 2011) or intellectual disability (Rispoli et al., 2011; Rivera, Wood, \& Spooner, 2012; Rohena, Jitendra, \& Browder, 2002; Spooner, Rivera, Browder, Baker, \& Salas, 2009). Others have focused on children with language impairment (e.g., Ebert et al., 2014; Pham et al., 2015; for reviews, see Kay-Raining Bird et al. in this issue and Thordardottir, 2010). Together, these studies suggest that intervention in a student's home language can have a positive effect for children with a variety of DDs and that instruction only in the majority language may overlook a potentially beneficial avenue for intervention.

\subsection{Access to language programs by language-minority students with disabilities}

In many countries, language education programs and services that support bilingualism are available to students in schools. The programs and supports that are available will vary with location. These might include language programs provided exclusively in the majority language, such as Dutch as a second language (DSL) programs in the Netherlands and English as an 
Additional Language (EAL) or English as a Second Language (ESL) programs in Englishspeaking countries. Other educational programs use students' home language as the medium of instruction in order to either facilitate the transition from the home language to the majority language, or to continue to develop the home language in addition to the L2, such as bilingual education programs in some areas of the U.S. (Díaz-Rico, 2012). In Canada, where children have a right to education in either of the two official languages (English and French), French Immersion programs are prevalent in English-majority communities (Genesee \& LindholmLeary, 2014). Additionally, the location of these services vary within and across contexts, with most available as part of the local schools' programmatic offerings in mainstream settings. However, not all types of programs (e.g., French Immersion in Canada or Dual Language Immersion in the U.S.) are available within all regions or even all schools within a region. Although policies suggest that children with DD can be included in language programs and support services (see Pesco et al., this issue), little is known about their access to these programs. The extent to which students with DD are actually able to access those language programs is the focus of the present study.

One area of research in the United States provides some indication about the extent to which L2 learners with special needs have access to language programs. Research on the disproportionate representation of minority students in special education has a long history within the U.S. (e.g., Donovan \& Cross, 2002; Harry, 1994; Heller, Holtzman, \& Messick, 1982; Losen \& Orfield, 2002; Mercer, 1973). This research reveals complex patterns of both over- and under-representation of students from ethnic minority backgrounds, such as African-American, Native American, Hispanic, and Asian students, regardless of whether their primary home language is English or not. Indeed, the vast majority of these studies do not examine patterns of 
disproportionality with respect to home language background. Some researchers, particularly those working in the Southwest region of the U.S. where there is a relatively high population of students whose home language is other than English, have demonstrated that these L2 learners are disproportionately represented in special education programs (e.g., Artiles, Rueda, Salazar, \& Higaredo, 2005; de Valenzuela, Copeland, Qi, \& Park, 2006; Romero, 2014; Samson \& Lesaux, 2009; Sullivan, 2011). Several of these studies additionally examined the type(s) of settings where students receiving special education services are educated.

In one of the only studies that has systematically investigated the access of students with disabilities to language programs, Romero (2014) found that L2 learners from language minority homes receiving special education services during the 2013-14 school year in one school district in the Southwestern U.S. were significantly less likely to receive federally mandated language development services than their ELL peers who were not identified with disabilities. Additionally, while L2 learners with disabilities had less access than their typically developing peers to both ESL and bilingual education programs, this disparity was greatest for bilingual education programs. Specifically, Romero found that less than 9\% of L2 learners with disabilities were placed in bilingual education programs while more than $30 \%$ of L2 learners without disabilities were in such programs.

Also analyzing disaggregated records of all students receiving special education services within one school district in the Southwestern U.S., de Valenzuela et al. (2006) examined the disproportionate representation of students from a variety of ethnic groups, as well as language minority students, both in terms of special education identification and with regard to placement in different special education settings. These settings were defined consistent with U.S. federal reporting guidelines and ranged from the most inclusive (general education classrooms $80 \%$ or 
more of the time) to the most segregated (placement in a separate classrooms within the same school as typically developing students $60 \%$ or more of the time). While more segregated placements, such as separate schools and facilities do exist, the percentage of students assigned to those settings were not sufficiently frequent to be included in the analysis of setting. De Valenzuela et al. found that while, overall, students with special needs from minority groups (e.g., African-American, Hispanic, and Native American) were disproportionately placed in the most segregated educational settings, L2 learners were placed in segregated settings at the highest rate of all groups studied. These authors found that almost $60 \%$ of L2 learners with special needs were educated in a segregated special education classroom for the majority of their day. They suggested that the disproportionate placement in segregated settings may be a "special concern" (p. 437) for L2 learners due to decreased access to language learning opportunities in segregated settings. Sullivan (2011) found a somewhat different pattern of placement across school districts in Arizona. As in the de Valenzuela et al. study, Sullivan found that L2 learners were less likely to be placed in an inclusive setting as compared to White students, the vast majority of whom were majority language speakers; however, she did not find an overrepresentation of L2 learners in fully segregated special education classrooms.

Taking a different approach, Artiles et al. (2005) examined data from 11 school districts in California and studied the relationship between (a) the enrollment of L2 learners receiving special education services in language programs defined by that state's education department, namely bilingual education, English immersion, and modified English immersion; and (b) L2 learners' placement in different special education settings. According to these authors, in modified English immersion in California, an authorized bilingual teacher provides instructional support in the student's home language for the purposes of concept development, whereas in 
straight English immersion, a paraprofessional may provide support in the home language for clarification purposes. In contrast, bilingual education programs provide content instruction in both the home language and English by certified bilingual educators. Artiles et al. reported that students in bilingual education programs were much more likely to be educated in less segregated educational settings than their peers who received either English immersion or modified English immersion services. They also found that students receiving modified English immersion were more likely to be educated in a less segregated setting than those in a straight English immersion program.

This literature suggests that access to language programs may be limited for L2 learners identified with disabilities, including those with DD, at least in the U.S. It is unknown whether L2 learners with various types of disability differ in the likelihood that they will experience restricted access to language programs. However, current research on access to general education settings (e.g. McLeskey, Landers, Williamson, \& Hoppey, 2012; Smith, 2007) suggests that students with intellectual disability have less access to inclusive settings than students identified with other disabilities, such as learning disabilities. The literature suggesting L2 learners with special needs and students with DD in particular have restricted access to the general education classroom is relevant because of observations of high rates of passive student engagement with the academic content (Pennington \& Courtade, 2014) and limited opportunities to engage with peers in meaningful communication (Downing, 1999) in segregated classrooms. While such findings may be troubling for all students placed in such an environment, they may be of even greater concern for students who must develop an L2 in such an environment and who also often have language learning difficulties due to their disability. Clearly, additional research examining the environments in which L2 learners with DD is needed since the vast majority of the studies 
have been conducted in the Southwest U.S. with L2 learners from language minority homes.

Research using existing databases with narrowly defined variables (e.g. ethnicity, disability, language proficiency status), such as those studies reviewed above, are useful for documenting patterns of disproportionate representation, but also have limitations. For example, they cannot tell us why certain inequities exist. Qualitative research, such as the study reported here, has the ability to address such issues by providing rich descriptions of phenomena and the contexts surrounding them (Lincoln \& Guba, 1985). Additionally, such designs allow for the emergence of analytic categories and insights that might not otherwise be examined when the analytic scheme is defined a priori (Guba \& Lincoln, 1994). As such, research using key informant interviews and grounded in the naturalistic paradigm is a complementary approach to the extant quantitative literature.

\subsection{Purpose of the Study}

This investigation is part of a larger interview study in which multiple aspects of the participation of children with DD in language and special education programs or services were examined at six sites in four countries. In the resulting analysis, a number of general themes emerged, one of which was the inclusion and exclusion of students with DD in and from bilingual opportunities. In the portion of the larger study reported here, we undertook to examine this general category and related subthemes in detail. The questions that guided the analysis reported here were:

1. What issues did the interviewees raise related to the inclusion and exclusion of students with DD in and from bilingual opportunities?

2. What are the similarities and differences across sites with regards to Question 1?

\section{Methodology}


Key informants (policy makers, professionals, and advocates) were interviewed regarding their experiences and beliefs regarding bilingual opportunities for children with developmental disabilities across six sites internationally: three in Canada [Vancouver, British Columbia (BC); Montréal, Québec (QC); and Halifax, Nova Scotia (NS)]; one in the United States [Albuquerque, New Mexico (NM)]; and two in Europe [Manchester, England, United Kingdom (UK) and Nijmegen, Netherlands (NL)]. To avoid confusion, henceforth in the text we will refer to each site in Canada and the U.S. by city plus province/state (e.g., Halifax, NS), in the UK by city plus country (Manchester, UK), and in the Netherlands by country only (to reflect the recruitment strategy used at that site, see below). We selected a semi-structured interview format because it allowed for inquiry into select topics of interest with consistency and comparability across international sites, and provided opportunities for elaboration and follow-up based on informants' unique experiences and beliefs. This structure also permitted flexibility and sitespecific inquiries, maximizing relevance for all informants, and allowing for insights into intersite differences.

\subsection{Participants}

Seventy-nine professionals with expertise either in special needs and/or language education (e.g., L2 instruction), participated in one-on-one interviews about service delivery and/or policy in these areas. These key informants included policy makers, professionals, and practitioners with experience working in either language services and/or special needs services in the city or country of interest for at least five years; purposive sampling was used to include participants with expertise in the topics of interest. Researchers in Canada, the U.S., and England recruited within the municipal areas specified above. The researchers in the Netherlands recruited participants from throughout the country, due to the relative population and geographic 
size of the Netherlands, in comparison to the other research sites. This ensured that all informants had adequate experience in the geographic region of interest to report on relevant access issues. This target group was selected because these individuals have direct knowledge regarding the availability, frequency, supports, and barriers related to bilingual opportunities for children with DD. We believed these informants would provide the most in-depth and accurate assessment of program availability. An effort was made at all sites to include informants from multiple disciplines and positions, allowing for variability and representative perspectives. Major organizations and institutions (e.g., regional school boards, government or local authority divisions, community or language programs, early intervention programs) in each area were contacted in order to identify key personnel in the field of interest. Upon recommendation or appointment by an organization, potential informants were contacted directly to determine interest in participation. Up to 15 informants were recruited from each site, with the final number of participants varying according to informant availability and the range of services for that area. A final sample of 79 informants ( 17 male, 62 female; $M=49.82$ years, $S D=9.90)$ participated across all sites. See Table 1 for a breakdown of site-specific demographics.

<Table 1 here>

Forty-eight informants reported being bilingual or multilingual themselves, and 33 reported using more than one language in the workplace. However, the majority of participants reported that the primary language of their workplace was the same as that in the community at large: English in Halifax, NS; Vancouver, BC; Albuquerque, NM; and Manchester, UK; Dutch in the Netherlands; and either English, French, or both, in Montréal, QC. Researchers at each site attempted to recruit participants who worked in a variety of workplaces (e.g., preschool education and other school settings, clinics and other community service provider agencies, 
governmental units, and parent advocacy organizations) and who held a variety of positions. At all sites, there was a mixture of participants who (a) directly provided services to children identified as L2 learners, potential L2 learners, and/or requiring special education services; or (b) oversaw the provision of the services, either in a supervisory or policy development capacity.

\subsection{Interview Procedures}

Each informant completed one interview with a trained research assistant or researcher, typically lasting between 60-90 minutes. As a team, a common interview protocol was developed and used to train those who conducted the interviews via videoconferencing. The interviews followed a consistent structure and were guided by target questions across sites (see Appendix A). Site-specific questions or informant-specific follow-ups were incorporated as appropriate to the context. An effort was made to capture the informants' views and experiences from both a language services perspective as well as a special needs services perspective. However, priority was directed towards the informant's domain of experience. Participants also completed a brief demographic questionnaire.

To maximize informants' comfort with the interview process, informants selected the appointment date, time, and location. All interviews were conducted in the informant's preferred language (English, French, Spanish, or Dutch). All interviews were audio-recorded and transcribed verbatim using a simple transcription protocol (Dresing, Pehl, \& Schmieder, 2012). Repeated words, word fragments, fillers (e.g., uh), contractions, abbreviations and grammatical constructions were transcribed as spoken. Additional conventions included using a comma to indicate a brief pause, a period enclosed within parentheses for longer pauses, and an asterisk to indicate a partial word and capitalizing words that were spoken with particular emphasis. Transcripts were completed in the language(s) spoken during the interview and used the spelling 
conventions of the country in which they were recorded. The excerpts below follow these conventions. Any identifying or personally sensitive information was anonymized using standard protocols. Following transcription and review, member checks were offered to each informant, to allow for correction, clarification or addition of content.

\subsection{Thematic Analysis}

The initial thematic coding scheme was developed by the first three authors (representing the Halifax, NS and Albuquerque, NM sites) based on review of a sample of interviews from all sites (including translated interviews from the Netherlands site) and was then refined by coding additional interviews and engaging in extensive discussions regarding these emergent themes. We identified and discussed salient excerpts, and documented our emerging understanding of themes, by developing definitions of each that we refined over time. We used an Internet-based, qualitative software program, Dedoose (Lieber \& Weisner, 2013), to facilitate collaborative development of the codes and to monitor coding in progress. The initial coding scheme was modified (by adding, altering, removing, or combining codes) as additional transcripts were reviewed. Throughout this process, we developed operational definitions of each of the codes and systematically reviewed previously coded transcripts to ensure consistent applications of the revised codes and verify that the finalized codes were indeed appropriate.

Once the structure of thematic codes was stable, we compiled the individual operational definitions and general directions for coding into an elaborated coding manual. Two coders from the four remaining sites (Vancouver, BC; Montréal, QC; Manchester, UK; and the Netherlands) were trained on the coding scheme system by the third author prior to beginning transcript review, using a sample of the interview transcripts in a mock-up of the actual project on the Dedoose website. Following explanation of the coding scheme, each novice coder worked 
through a sample transcript and that coding was then reviewed by the third author for accuracy. Any differences in coding were discussed in order to achieve a uniform understanding of the codes and coding process. Each transcript was coded by a researcher or research assistant at each site and then reviewed by a secondary coder, consisting of one of the three primary authors. Differences in coding were resolved through the use of memos and, as needed, live conversations by telephone or voice-over-Internet. Care was taken to objectively code the informant's explicit statements and intentions, with limited interpretation on behalf of the coder. As questions arose regarding operational definitions of any of the themes, these were clarified in the coding manual and distributed to all researchers and research assistants, so that re-coding of particular excerpts or transcripts could be undertaken, as needed. While all transcripts were coded in the language spoken during the interview to preserve content and intention, for non-English transcripts, key statements or excerpts were summarized in an English translation for the sole purpose of understanding across all researchers. In the final stage, each of the codes were reviewed to extract the main, recurring themes within and across sites.

\section{Results}

The results of this analysis of the key informant interviews revealed a number of themes specifically related to the inclusion and exclusion of students with DD. Whether, and the extent to which, students with DD have access to and participate in programs or services that support bilingual or L2 development was an overriding question for this project as a whole. This included not only the key informant interviews, but also the document and policy analyses and the survey reported in other articles in this special issue (Marinova-Todd et al., this issue; Pesco et al., this issue). Therefore, inclusion/exclusion was, to a great extent, an analytic category determined a priori by our research design and interview questions. However, the sub-themes 
within this category, as well as how we came to understand this category in general, emerged as a result of the analytic process described above. Throughout the results, the key informants will be identified by a site code reflecting the previously defined acronyms for state (NM), province (NS, QC, BC), or country (UK or Netherlands-NL) of the informant and a within-site numerical code (number 1-15) that references the specific transcript. In the following, we describe this parent code, inclusion/exclusion, as well as the child codes within this overall category.

\subsection{Inclusion/Exclusion}

Both this theme in general and its related child codes together focus on factors that impact: (a) the inclusion/exclusion of children with special needs in and from language programs; (b) the inclusion/exclusion of L2 learners in special needs programs and services; and (c) the inclusion/exclusion of L2 learners with special needs in and from other bilingual experiences or opportunities. Throughout this analysis, we focused specifically on students with special needs, including but not exclusive to L2 learners. Statements that explicitly applied only to L2 learners without special needs were not pertinent to this analysis and were therefore neither coded nor included in the analysis. Excerpts coded into this category were reviewed during the development of the coding scheme in order to determine whether any of the participants' remarks were similar enough to warrant development of a child code. As we examined these excerpts, six child codes emerged: we include all kids, special needs drives it, time/scheduling conflicts, IEP/IPP/statement drives it, it's up to the parents, and service availability. Excerpts that remained within the parent code were those that were general in content, such as statements that students do or do not participate in particular programs, and did not relate to any of the child codes. More detailed comments that were not shared across participants and did not reach 
saliency as a child code also remained within the parent code.

3.1.1 We include all kids. Informants at all sites commented that inclusion of children with special needs was a goal and that the educational institution or system they discussed had an inclusive philosophy. For example, one informant in Montréal, QC explicitly stated that "we follow an inclusive model" (QC4), a Manchester, UK informant said "that would be your aim, like any child with a developmental disability, inclusion” (UK1), and a Vancouver, BC interviewee referred to the school district's "commitment to inclusion" (BC11). In a similar vein, an informant from the Netherlands commented that "they take part in our program, and if special care is needed, that is taken care of" (NL2). In these excerpts, the participants were referring to students with disabilities accessing general education classrooms, programs, and services. While inclusive principles were discussed at all sites, different programs were identified as inclusive at different sites, such as English programs (the Netherlands), French schools and intensive French programs (Montréal, QC), HeadStart preschools and a school district as a whole (Albuquerque, NM), language classes (Halifax, NS, and Montréal, QC), and licensed daycares (Halifax, NS).

All sites also identified strategies to assist L2 learners with special needs to participate in general education classrooms, recognizing that supports are necessary for inclusion: "when we are able to have a diagnosis and provide support for these kids, we can almost get them participating in anything" (BC13). These supports included having and working with the necessary staff. For example, one Montréal, QC informant commented that "whether it's an integration aide or working in the resource room teacher ok but there are adaptations for those students for sure" (QC5). Similarly, a Halifax, NS participant noted that "the principles of inclusion also include a trans-disciplinary approach. And so that a child care facility is working with other uh professionals and other service providers to provide uh a good program for 
children" (NS13). Additionally, it was affirmed across sites that students in inclusive settings would still have access to special needs services. Even though inclusion was stressed by participants across all sites, informants also acknowledged that it was not practiced uniformly across the board. A Montréal, QC interviewee said "you know it's inclusion for all students but we also RECOGNISE that it doesn't work for all students” (QC9).

In Canada, informants stated that children with DD were likely to be included in minority official language classes (i.e., French classes in Halifax, NS and Vancouver, BC; English classes in Montréal, QC). A number of informants at these sites referenced the mandatory nature of these language classes for all students, such as these informants from Halifax, NS and Montréal, QC, respectively: “cause all students uh receive that uh uh those courses [French language classes] from grade four to uh to nine" (NS4) and "it's [participation in English classes] not an option; it's an obligatory course. It's a requirement uhm for the program of studies in Québec" (QC7). Respondents in Halifax, NS and Vancouver, BC also reported students having access to ESL or EAL support; “in our board, in EAL we do support all learners” (NS7). Yet, even where programs are mandatory, some respondents indicated that, for students with DD, there might be leeway in terms of the requirement to participate, especially if parents requested such an exemption or a decision to exempt was made in a child's program planning meeting. For example, even though ESL services are federally mandated in the U.S., participants recognized that choices were often made between special educations services and ESL: "if the IEP team, if there's not someone there who's really advocating for that home language or recognizing it, even if they don't say it...the message is sent...That it needs to be English. That the services need to be (.) you know speech and language rather than ESL or, not a combination of both" (NM6). We will discuss the role of parents or program planning meetings in exemptions from mandated 
language programs in a later sections, it's up to the parents and IEP/IPP/Statement drives it.

In contrast to language classes, participants reported less inclusion of students with DD in other, non-required language programs and services. For example, when discussing whether students with DD with communication difficulties would participate in French Immersion programs in Montréal, QC, an informant commented that "immersion schools are very uh, intense (laughs). Uh, yeah it's a serious program that, you know, we want the students to succeed and if they're held back because of the language of instruction that's not fair to anyone" (QC9). There seemed to be good consensus that access into these programs should not be denied: "I think that the communication has been quite, uhm, direct. That there's to be no discrimination in you know in bilingual programs. Uhm and that all kids have to be, accepted should they want to" (NS2). However, this Albuquerque, NM respondent, similar to others, discussed that access to many language education programs was indeed limited: "we don't have special ed students in the dual language program" (NM11). While most did not state it this bluntly, it was clear that the ideals of inclusion did not carry over as systematically as some of the informants might have wished.

Additionally, as we discuss in the theme below, special needs drives it, there was also a clear relationship between access to language programs and special needs diagnosis, with students with more severe disabilities not having access to inclusive settings and to language programs that are a part of general education. This segregation of students with more severe disabilities was recognized even when inclusion was mentioned as a philosophy or organizing principle. Another respondent from the Albuquerque, NM site, discussing heritage language classes for Native American students offered at a centralized district location, stated that "we have not kept out any students uhm Native American students from taking our classes, if they 
wanted to take this as an elective class" and "we include everybody" (NM13). Yet, this informant also recognized that while transportation for general education students to attend these programs was available, students in segregated programs within these same schools did not have access to this transportation to attend: "they're [students with severe disabilities in segregated programs] not bussed out of their school, to come to the programs" (NM13). This excerpt makes explicit the relationship between education in inclusive settings, access to language programs, and severity of disability, which will be discussed in more detail below.

3.1.2 Special needs drives it. While there was a stated adherence to inclusive principles in some programs at all sites, our analysis also suggested that, when faced with choices for program planning for students identified with disabilities, there tended to be an "either/or" type of thinking, with special education needs taking precedence over language programs: "I think the developmental disorder would be seen as the more important aspect of er hm, rather than the bilingualism" (UK2) and "with regard to children with lower cognition, we are happy enough when they can deal with the Dutch language, that is the priority, and then the language spoken at home" (NL5). This primacy of special needs services over language programs seemed most apparent for students with more severe disabilities and those with significant communication difficulties. This was a consistent factor noted by participants as influencing decision making, as in the following excerpts: "It clearly depends on the severity of the disability" (QC9) and "it just depends on how severely their language system is, has been impacted" (BC3).

Excerpts within this child code were frequently also coded with a theme not reported on in this analysis, beliefs about bilingualism, second language learning, and special needs, as seen in the following excerpt:

But I think it's if they've got a language impairment, which means that they're struggling 
to acquire even English it's difficult. I mean I don't know if this is advice anyone else would give but I find it hard to justify spending time learning another language when they need to put that time in to learning English, which is the case for a lot of children with language impairments you know have delayed language skills as well. (UK12)

In this excerpt, as in others where informants used phrases like "the added pressure of learning another language" (NS4) or "extra load" (BC1), these respondents made explicit their belief that learning two languages is more difficult than learning one and that perhaps should not be prioritized for students with DD. Therefore, if a student has learning challenges, they might be removed from or not enrolled in a language program. For example, one Montréal, QC participant stated that "we have to look at the individual students. Uh, often, we will recommend that the student, if they are really struggling, not be in an immersion program" (QC9), thereby exempting them from the policy of including children of all abilities from an Anglophone background in French Immersion schooling. At the same time, respondents across sites affirmed that inclusion into language programs should be considered on a case-by-case basis and reported that students with DD are not categorically excused: "there are students in all the programs with developmental disabilities" (QC9). Additionally, a number expressed their belief that students with DD should be supported to learn two languages, such as in this excerpt: "why can't they be in a bilingual program, or dual language program?” (NM11).

Another aspect of the theme special needs drives it was the recognition that disability severity was often linked to segregated special education placements: "If you have a student who has a (.) that's of lower cognitive ability, they typically get moved into an intensive special ed program and language is secondary" (NM10). Moreover, segregated educational settings were linked to reduced access to language programs, even those considered mandatory, as in this 
example from Halifax, NS: "If a child is a profoundly disabled to the point where they spend more than half their time in the learning centre. That that's the only time we would consider uhm them being able to opt OUT automatically from a French program" (NS10). Many of the bilingual or L2 learning programs were discussed as only available to children spending the majority of their time in general education programs, not segregated special needs settings. The following excerpt from a Manchester, UK informant reinforces this conflict between special needs and language education programs and supports: "I think if they did have a complex disorder I think they would be managed through the special needs department and probably would be involved in their interventions and therefore might lose out on the EAL interventions" (UK2). In contrast, students with more mild disabilities were reported to have relatively greater access to inclusive settings, and therefore, to language programs available in those settings: “those students [with learning disabilities or reading difficulties] they're usually in inclusive settings so they come to a bilingual class for that 45 minutes of of Spanish language instruction" (NM6).

3.1.3 Time/scheduling conflicts. Time and scheduling conflicts, as a factor in determining what services students would receive, were largely discussed only in the Albuquerque, NM; Halifax, NS; Manchester, UK; and Netherlands interviews, with this raised as an issue most frequently by Albuquerque informants. For those who addressed this issue, they recognized that there is often scheduling competition between special education and language services, as related in the following statement:

Once they get to secondary school it's tricky because you know schools will advise that they need to be taken out for social skills programmes, for behaviour programmes, for additional literacy, for language programmes. So you know, you think where is all this 
time gonna come from? Where are you going to withdraw them from? So and so that's a difficult issue. So there's arguments for every subject they need to be in there. But somehow they need all these intervention programmes as well. (UK6)

This idea was reiterated in other interviews, as in the following: "the more special ed help they're getting, I would say that less, ESL, ELL help is all that they have time for" (NM03). Or, as stated by a participant from the Netherlands: "Especially when more time and more money would be available, more could be done. That's the big problem always, I guess" (NL8). In addition, concerns were also raised about limited time available to assist students with disabilities in the general education classroom.

3.1.4 IEP/IPP/Statement drives it. Informants at all sites except the Netherlands discussed the importance of the Individualized Education Plan (IEP; U.S. and parts of Canada), Individual Program Plan (IPP; parts of Canada), or Statement (UK) in making program decisions: "it really depends on what the IEP committee sees" (NM3). Related to this, informants recognized these processes may not support the bilingual needs of a child:

We no longer have a culture where it is just common practice to exempt students from learning a second language no matter what... Is it still happening? Yes I would say it is. But uh the process that allows it to happen now is the program planning uh process at the school...it has to go through uh the program planning team at the school. (NS4)

Furthermore, reported recommendations for supports differed both within and across sites, even when bilingual needs were addressed in the student's IEP, IPP, or Statement. For example, one informant in Manchester, UK stated that “if they've had their Statement through and got some special educational needs we state that if they need treatment in their home language that they would need a classroom assistant who spoke home language" (UK8). However, as we describe 
under service availability, informants reported difficulty in staffing such positions. The different types of supports for bilingual needs were not addressed here, as they are captured within another major analytic category, accommodations, examined in a separate analysis. Regardless of the type of accommodations that could be provided, several informants in Albuquerque, NM reported that supports for L2 development should always be addressed in the IEP. However, these informants also recognized that best practices in this regard are not consistently followed: "I still question sometimes (if) if there was someone who understands second language acquisition on the IEP team" (NM6). A critical aspect of this theme was the affirmation by participants that the IEP, IPP, or Statement process is where determinations regarding supports for both special needs and language should be, and are, made.

3.1.5 It's up to the parents. Across sites, informants placed considerable responsibility for initiating and making decisions about whether students would or would not have access to specific language programs or services in the home language upon parents. However, this theme occurred much less frequently in the transcripts of the Manchester, UK and Netherlands participants. In the following excerpt, the Vancouver, BC interviewer asked about a hypothetical situation where a parent of a child with Down syndrome wanted that student to attend French Immersion:

Uhm if, you know, there again, I think we'd look into circumstances. If they're a FAMILY that/ we'd probably have a conversation with him around maybe this wouldn't be the best/ necessarily the best educational fit for their child. Uhm, I don't think we would refuse to allow them to go //in//. I think we'd just work around it. To be honest with you, we've never had that come //up//. Uhm, I think, just like anyone, when we feel that the disability is/ French immersion would have an impact/ Because of the disability, 
French immersion may not be the best choice for them, we'd have that conversation. Just like a kid, where we feel like because of their huge issues with long term retrieval, the French may not be the best, we'd have the same conversation with a family with Down syndrome. But at the end, I think if they really were insistent that they go in French Immersion, we'd put supports in, we'd support the student and then hopefully, have review and have that conversation on an ongoing basis and take it from there. But I don't think we'd say “you can’t go in.” (BC7)

Similarly, another Vancouver, BC informant remarked that "I think to become bilingual, if parents are uhm advocates or good advocates then they could get access to certain other languages to become bilingual" (BC1).

In addition to requesting services, respondents recognized parents' right to decline language services or supports. For example, in Albuquerque, NM, participants referenced parents' rights to request a waiver of alternative language services (e.g., bilingual education or ESL), and in Montréal, QC, to request an exemption from mandatory French schooling. Informants across sites noted a variety of reasons why parents might make choices regarding language programs, a number of which are summarized in the following excerpt:

I've had lots of families reflect on this with me. So sometimes they think you know that he's going to live, in an English-speaking place. He's gonna go to school in English. And so we think it would be best if we focus on his English. Uhm others stay committed sometimes from necessity and sometimes from conscious choice to their first language. And by necessity I mean sometimes the people living in the home who don't SPEAK English and so they're going to be speaking their first language at home. And $i^{*}$ you know obviously the child continues to hear that language. And then the BIG THING is uh 
for school, is this child going to the English stream? (.) Francophone? Do they CHOOSE French immersion? So choosing bilingualism and uhm again uh because we have uh uh an Arabic-language school option (that) that comes up for some families. (NS14) In addition, informants related some parents" concerns about overloading students: "if they believe that adding a second language will be, HARD and that could influence their decision" (NS4). The influence of such beliefs on decision making are similar to the intersection of programmatic decision making and practitioners' beliefs about bilingualism, L2 learning, and special needs described in the previous theme Special needs drives it.

3.1.6 Service availability. Informants at all sites discussed factors limiting language program availability for all children, including, but not restricted to, students with special needs. For example, when responding to a question about what might limit students with DD from attending language programs, such as Dual Language Immersion, Heritage language programs, or other bilingual education programs, an Albuquerque, NM informant stated that "I think the biggest thing that there's not a lot of them" (NM7). One factor noted in limitations in service availability was geography: "Students who are zoned for a particular school will be exposed to whatever models are available in that school in their zone" (QC7) and "there's not universal early French Immersion...So geographically depending on where you are you may not BE ABLE to access French Immersion until grade 7" (NS10). Another factor noted was funding, both in terms of funds to develop and maintain programs, as well as funding for specialized staff, including those who speak non-majority languages. Also, especially in the Canadian contexts with regard to services provided to Indigenous students, jurisdictional conflicts were cited, as illustrated in the following excerpt: "When the province unleashes a program... and says it's available for all... and then you apply for the process says 'Oh wait a second you're federally 
funded, this is provincial, it's not available to your communities"” (NS9).

Finally, lack of special needs services in the target language was reported to limit the access of students with special needs to language programs, especially in Halifax, NS;

Vancouver, BC; Manchester, UK; and Albuquerque, NM. Some informants reported lack of staff influenced programmatic decision making or service delivery: "It may be written it may be uhm, part of the plan but it's just not offered or is consistent. Uhm, uhm, (.) and then second of all I think a lot of it also is, is that they don't have the the staff, to provide, the support" (NM5). At times, staff shortages was reported to be related to lack of funding, but not always. Regardless of whether funding was available or not, informants decried a lack of staff who could speak the variety of languages needed: "Because we don't have a therapist that speaks another language we can't invite a child, whose first language is Urdu say" (UK12). This scarcity was referenced to both specialized staff (e.g. therapists and teachers) and educational assistants and other support staff. This concern was noted by participants across sites.

\section{Discussion}

In this study, we examined the inclusion (or exclusion) of children with DD in language education programs and services. Results suggested that children with DD, especially those with more severe disorders, have limited access to some L2 education programs and services, which reduces their opportunities to become bilingual. Several barriers to access and participation were identified, some of them common across sites. Further, parents of children with DD could request that their child be enrolled in some L2 education programs but also needed to be strong advocates if their child was to participate. Furthermore, parents could, and did, exempt their children with DD from L2 education programs, even when they otherwise would have been required. The program planning committee (IEP/IPP/Statement) was often cited as the 
appropriate place for placement decisions to be made. These issues are discussed further below.

\subsection{Access to Language Programs}

Inclusion as a philosophy was embraced by informants at all sites. Also, policies affirmed that children of all ability levels could participate in the L2 education programs available at all sites (Pesco et al., this issue). However, when informants discussed the actual participation of children with DD in L2 education programs, it was evident that children with DD were more likely to be included in some programs than others, as reported in the results above.

The finding that children with DD have reduced access to bilingual education (i.e., instruction provided in both the minority and majority language of the child) in Albuquerque $\mathrm{NM}$, the only site where these programs are routinely offered, is consistent with Romero's (2014) finding that children with special needs rarely participated in bilingual programs in one school district in the Southwest U.S. It is concerning that informants report reduced access to bilingual education programs in particular as there is considerable evidence that language and academic achievement is better for typically developing L2 learners in these programs than when English is the only language of instruction (e.g., Collier \& Thomas, 2009; Genesee \& LindholmLeary, 2014; Thomas \& Collier, 2012). There is also emerging and complementary evidence that children with DD do at least as well academically in dual language immersion programs compared to English-only programs (Myers, 2009).

It is not surprising that informants' reported reduced access and participation of children with DD in French Immersion programs in Canada. In his review of studies of at-risk children in French Immersion programs, Genesee (2007) reported that many children who experience academic or language-learning difficulties in French Immersion transfer out of the program. Interestingly, those who transfer to programs where English is the only language of instruction 
do not necessarily do better, either academically or in English language development; and, of course, only the children in the French Immersion programs develop functional French language and literacy skills (Genesee, 2007). To our knowledge, there are no published studies of children with DD in French Immersion. However, Hodder, Merritt, and Kay-Raining Bird (2014) documented substantial French and English language and literacy skills in one child with Down syndrome who had attended French Immersion for four years.

While children with DD were reported to participate in ESL/DSL programs at all sites, in Albuquerque, NM informants stated that parents could and did exempt their children with DD from these services, perhaps especially when there were timing and scheduling conflicts with special education services. ESL/DSL services are offered to facilitate development of the majority language in children with a minority home language. Certainly, such services would seem to be particularly important for children with DD when they first are immersed in a majority language, as they already struggle with language development. That being said, there are no studies we are aware of that have investigated the effectiveness of ESL/DSL programs for children with DD. It is possible that educators and parents see speech-language pathology or other special education services, which are often offered only in the majority language (e.g., Caesar \& Kohler, 2007; D’Souza, Kay-Raining Bird, \& Deacon, 2012), as a sufficient method for supporting majority language development in children with DD and therefore view ESL programs as redundant or unnecessary. If this is the case, our informants did not mention it, but this interpretation would be consistent with reports across all sites that, when scheduling conflicts occur, special education services 'trumped' L2 services for children with DD.

There are several implications of the findings just discussed. First, practice does not always follow policy. When services are mandated (such as is true of ESL services in 
Albuquerque NM), children with DD do not always receive those services. It seems appropriate that efforts be made to ensure that they do. To this end, participation could be placed in a student's IEP/IPP/Statement with the conditions for participation delineated. In addition, even when program participation is not mandated, practices should be examined to ensure that they are consistent with a philosophy of inclusion, a philosophy embraced by the key informants in this study and endorsed in the policies of all sites (Pesco et al., this issue). It is likely that many students with DD could be included in various language programs and would benefit from inclusion, with appropriate special education supports. In particular, bilingual education should be a serious consideration for children with DD given its proven efficacy as described above (e.g., Collier \& Thomas, 2009; Genesee \& Lindholm-Leary, 2014; Hodder et al., 2014; Myers, 2009; Thomas \& Collier, 2012). Finally, it is of critical importance that greater inclusion be accompanied by focused research to document the language and academic outcomes of children with DD in various language education programs and what factors influence their success.

\subsection{Barriers to access and participation.}

Restrictions to the availability of language education programs and bilingual supports were identified at all sites. This is a barrier that affects all students, not just those with DD. Informants described geographic restrictions on program or service availability, sometimes but not always related to funding or staffing limitations. When unable to fund or staff programs or services, school boards may need to strategically place them in locations with a higher or a criterion level of need due to funding and staffing limitations. Policies or laws will also impact funding availability by identifying priorities and providing focused support. For example, education in both official languages is mandated by federal law in Canada and, therefore, funds are available to support language programs in the minority official language in communities. 
Similarly, language support services for language minority students whose development of English is still limited are mandated by federal law in the U.S. and, therefore, ESL programs are found in virtually all New Mexico K-12 schools. Staffing shortages may result from a shortage of qualified personnel. For example, in L2 development programs, DSL/ESL certified instructors may not be available. In the UK, where children from minority language backgrounds are taught in the majority language_English—classroom assistants assigned to children with special needs may not speak the child's minority language and therefore cannot help bridge L2 development. In Canada, where Immersion programs are typically housed in schools in which most children are taught in the majority language, resource teachers may not be bilingual and therefore can only provide remedial reading and math instruction in the majority language. Several of these shortages reduce access to special education services which, in turn, further discourages parents from enrolling their children with DD in some language education programs. Indeed, KayRaining Bird et al. (2012) and Yu (2012) both reported that parents of children with autism spectrum disorders were discouraged from raising their child bilingually when special education services were only provided in the majority language. Our findings emphasize the need for collaboration to maximize staff with knowledge of students' home languages, including general and special education staff and educational assistants, in a systematic and planned manner.

Time constraints were identified as another significant barrier. Informants discussed the challenges involved with juggling multiple, and often complex, needs of children with DD within a limited time period. Bilingualism adds another level of complexity to this mix. When scheduling conflicts were discussed, special education services often seemed to trump or be prioritized over language services. Interestingly, in these cases, language education and special education seemed to be competing rather than integrated services, provided by different people, 
at different times, and in different physical locations. It is possible that use of more collaborative models that employ co-teaching and/or push-in rather than pull-out services might reduce some of the time pressures that admittedly exist. Perhaps also the assumption that one service is more important than the other needs to be reconsidered. Is it necessarily more important that students are in special education than language education programs? Perhaps there is a way for students to receive their special education services within language education programs, or their language education programs as a component of their special education services through collaborative program development.

The presence of a severe disability appears to be an important barrier to participation in language education programs and services designed to support bilingualism. Even when a program was said to be mandatory, such as French language classes in schools with English as the language of instruction in Halifax, exceptions were made for children with severe disabilities who spent the majority of their time educational time in separate classrooms. Marinova-Todd et al. (this issue) reported similar findings from survey data. Bilingual children with severe DD were reported to participate less often in ESL/DSL programs and were more likely to be educated in the majority language than typically developing children or those with mild DD. Further, they were less likely to be enrolled in Immersion and bilingual education programs or foreign language classes and they were considered less capable of becoming bilingual. Of course, it is the case that a severe DD will impact development in both languages of a bilingual child. However, there is evidence that even children with severe DD can become bilingual and that there is not a one-to-one correspondence between severity and growth in each language (e.g., Hambly \& Fombonne, 2014; Kay-Raining Bird et al., 2005; Kay-Raining Bird, Lamond, \& Holden, 2012). In addition, many children with severe disabilities need to communicate in two or 
more languages. Furthermore, students in the process of developing language need ample opportunities to interact with peers who have well-developed language skills. Downing (1999) argued that the general education classroom is where this support is most likely to be available but, as de Valenzuela et al. (2006) reported, L2 learners are more likely than any other groups to be placed in highly restrictive segregated contexts. This segregation may be particularly problematic for L2 learners, as peer interaction is especially important for those in the beginning stages of developing a new language. It is important for us as a society to grapple with how best to support bilingualism in all children with DD, regardless of severity.

\subsection{Parents as decision makers.}

In the present study, the right of parents to make programmatic decisions for their children was affirmed. This is consistent with educational policy at all of these sites, which provides for parent involvement in determining students' education programs, such as via IEPs, IPPs, or statements. However, the responsibility of schools and other educational institutions to create an environment where these issues were openly discussed and where parents could be supported to choose among options was not recognized. It would appear that, in contexts where the parent of a typically developing child might be offered all options existing in a school, parents of children with DD often needed to ask and then advocate for their child to enter available language education programs. The 'ask' is often done during program planning meetings, when a child with DD is transitioning into the school system. In their classic study, Mehan, Hertweck, and Meihls (1986) examined the power differences between parents and professional staff in IEP meetings, and found that technical expertise and differential status played a role in who had a real voice in decision making. Many parents may not have the knowledge or cultural capital necessary to advocate effectively for language education services, 
especially if they are not fluent in the majority language or have cultural differences, lower education levels, or live in poverty. Therefore, an important implication of this research is that careful attention be placed on the unbiased presentation of all programmatic options for L2 learners with DD during team meetings, with the recognition that power differences may hinder parents' abilities to be effective advocates for their children, especially if they might desire program options that are not typical or are challenging for the school to meet. An informed discussion of such options requires that staff with in-depth knowledge of bilingual language development and language programs be present at team meetings and fully involved in decision making.

\section{Limitations}

Issues of access and participation are complex and multi-faceted. As with any qualitative study, the topics discussed are constrained by the questions asked and the interview techniques applied. In this study, which included interviews conducted in multiple sites, there undoubtedly were differences among the interviewers in style, amount of probing, and ability to encourage extended answers from participants, even with the training we implemented. Additionally, there was only one geographical site for the U.S., UK, and Netherlands, so perhaps these sites were not as representative of the diversity of opinion and practice evident by having three sites in Canada. However, these sites were chosen to maximize the number of bilingual children and therefore the potential for best resources and opportunities for DD who need to be bilingual, so these views may reflect the 'best case scenario' or contexts with the best chance for best practices, for those countries. Additionally, the situation in other countries, including those from developing nations where uniform access to special education many be limited, or other industrialized nations where the first and second languages have different orthographic systems 
(such as in China), was not examined in this study. Thus, while this study has provided important insights into access and participation for children with DD, there are areas that future studies must explore that the present study was silent on. These include a deeper understanding of why bilingual and special education programming are not more integrated and insights into sitespecific strategies for including children with DD in bilingual programs.

\section{Conclusion}

By definition, children with DD have developmental delays; these may be compounded by selectively exempting or excluding these children from bilingual programs or bilingual supports that might be important in facilitating their development as bilingual individuals and subsequent participation in bilingual contexts outside of school. For example, French Immersion programs are important for Canadian children from Anglophone backgrounds to learn French and speaking both French and English may facilitate their inclusion and participation in settings where different languages are used. This study has highlighted the presence of barriers that prevent access to or full participation in bilingual opportunities by children with DD. The informants in this study embrace notions of full inclusion which is consistent with current philosophies of special education world-wide (United Nations, 2006). However, as our informants reported, the application of inclusive principles to bilingual programs and supports needs considerable attention before this ideal can be realized. 


\section{Acknowledgements}

This research was supported by a grant \#890-2011-0150 from the Social Sciences and Humanities Research Council of Canada (SSHRC) to the second author. We acknowledge the support of additional investigators and research assistants at the research sites involved in this study: Maria Elena Corral, Lizett Gutierrez, and Billie Ramos-Schultz (Albuquerque); Pat Cleave and Bonita Squires (Halifax); Melissa Allen and Ella Perry (Lancaster); Myriam Beauchamp, Natacha Trudeau, Diane Pesco, Fred Genesee, Ann Sutton, Mélissa di Sante, and Alexandra Imperiale (Montréal); Ludo Verhoeven, Carolien van Campen, and Annegien Langeloo (Nijmegen); and Stefka Marinova-Todd, Paola Colozzo, Susan Fawcett, Roxana Radu, and Hillary Stahl (Vancouver). 


\section{References}

Artiles, A. J., Rueda, R., Salazar, J. J., \& Higaredo, I. (2005). Within-group diversity in minority disproportionate representation: English language learners in urban school districts. Exceptional Children, 71(3), 283-300.

Caesar, L. G., \& Kohler, P. D. (2007). The state of school-based bilingual assessment: Actual practice versus recommended guidelines. Language, Speech, and Hearing Services in Schools, 38(3), 190-200.

Collier, V. P., \& Thomas, W. P. (2009). Educating English learners for a transformed world. Albuquerque, NM: Dual Language Education of New Mexico, Fuente Press.

Dalmau, Y. C. P., Wacker, D. P., Harding, J. W., Berg, W. K., Schieltz, K. M., Lee, J. F., ... Kramer, A. R. (2011). A preliminary evaluation of functional communication training effectiveness and language preference when Spanish and English are manipulated. Journal of Behavioral Education, 20(4), 233-251. doi: 10.1007/s10864-011-9131-z

de Valenzuela, J. S., Copeland, S. R., Qi, C. H., \& Park, M. (2006). Examining educational equity: Revisiting the disproportionate representation of minority students in special education. Exceptional Children, 72(4), 425-441.

Díaz-Rico, L. T. (2012). A course for teaching English learners. Boston, MA: Pearson.

Donovan, M. S., \& Cross, C. T. (Eds.). (2002). Minority students in special and gifted education. Washington, DC: National Academy Press.

Downing, J. E. (1999). Teaching communication skills to students with severe disabilities. Baltimore, MD: Paul H. Brookes.

Dresing, T., Pehl, T., \& Schmieder, C. (2012). Manual (on) transcription. Transcription conventions, software guidelines \& practical hints for qualitative researchers $\left(2^{\text {nd }}\right.$ 
English ed.). Marburg, Germany. Retrieved from:

http://www.audiotranskription.de/english/transcription-practicalguide.htm

D’Souza, C., Kay-Raining Bird, E., \& Deacon, H. (2012). Survey of Canadian speech-language pathology services to linguistically diverse clients. Canadian Journal of Speech-language Pathology and Audiology, 36, 18 - 39.

Ebert, K., Kohnert, K., Pham, G., Disher, J., \& Payesteh, B. (2014). Three treatments for bilingual children with primary language impairment: Examining cross-linguistic and cross-domain effects. Journal of Speech, Language, and Hearing Research, 57, 172-186.

Genesee, F. (2007). French immersion and at-risk students: A review of research evidence. Canadian Modern Language Review, 63(5), 655-687.

Genesee, F., \& Lindholm-Leary, K. (2013). Two case studies of content-based language education. Journal of Immersion and Content-Based Language Education 1, 3-33.

Greenlee, M. (1981). Specifying the needs of a 'bilingual' developmentally disabled population: Issues and case studies. NABE Journal, 6(1), 55-76.

Guba, E., \& Lincoln, Y. (1994). Competing paradigms in qualitative research. In N. Denzin \& Y. Lincoln (Eds.), Handbook of qualitative research (pp 105-117). Newbury Park, CA: Sage.

Guralnick, M. J. (2006). Peer relationships and the mental health of young children with intellectual delays. Journal of Policy and Practice in Intellectual Disabilities, 3(1) 49-56. doi: $10.1111 / \mathrm{j} .1741-1130.2006 .00052 . x$

Hambly, C. \& Fombonne, E. (2014). Factors influencing bilingual expressive vocabulary size in children with autism spectrum disorders. Research in Autism Spectrum Disorders, 8(9), 1078-1089. doi: 10.1016/j.rasd.2014.05.013 
Harry, B. (1994). The disproportionate representation of minority students in special education: Theories and recommendations. Alexandria, VA: National Association of State Directors of Special Education.

Heller, K. A., Holtzman, W. H., \& Messick, S. (Eds.) (1982). Placing children in special education: A strategy for equity. Washington, DC: National Academic Press.

Hodder, C., Merritt, E., \& Kay-Raining Bird, E. (November, 2014). The experience of French Immersion by one child with Down syndrome and his family. Presented at the annual American Speech-Language-Hearing Association Convention, Orlando, FL.

Kay-Raining Bird, E., Lamond, E., \& Holden, J. J. (2012). A survey of bilingualism in Autism Spectrum Disorders. International Journal of Language \& Communication Disorders, $47,52-64$.

Kohnert, K., \& Medina, A. (2009). Bilingual children and communication disorders: A 30-year research retrospective. Seminars in Speech and Language, 30, 219 - 233.

Lang, R., Rispoli, M., Sigafoos, J., Lancioni, G., Andrews, A., \& Ortega, L. (2011). Effects of language of instruction on response accuracy and challenging behavior in a child with Autism. Journal of Behavioral Education, 20(4), 252-259. doi: 10.1007/s10864-0119130-0

Lieber, E., \& Weisner, T. (2013). Dedoose [on-line computer software application]. Retrieved from: http://www.dedoose.com.

Lincoln, Y. S., \& Guba, E. G. (1985). Naturalistic inquiry. Newbury Park, CA: Sage

Losen, D. J., \& Orfield, G. (Eds.). (2002b). Racial inequity in special education. Cambridge, McLeskey, J., Landers, E., Williamson, P., \& Hoppey, D. (2012). Are we moving toward educating students with disabilities in less restrictive settings? Journal of Special 
Education, 46(3), 131-140. doi: 10.1177/0022466910376670

Mehan, H., Hertweck, A., \& Meihls, J. L. (1986). Handicapping the handicapped: Decision making in students' educational careers. Stanford, CA: Stanford University Press.

Mercer, J. R. (1973). Labeling the mentally retarded. Berkeley, CA: University of California Press.

Myers, A. (2009). Achievement of children identified with special needs in two-way Spanish immersion programs. Unpublished dissertation. Graduate School of Education and Human Development, George Washington University.

Paradis, J., Genesee, F., \& Crago, M. B. (2011). Dual language development and disorders. A handbook on bilingualism and second language learning ( $2^{\text {nd }}$ edition). Baltimore, MD: Paul H. Brookes.

Pennington, R. C., \& Courtade, G. R. (2015). An examination of teacher and student behaviors in classrooms for students with moderate and severe intellectual disability. Preventing School Failure, 59(1), 40-47. doi: 10.1080/1045988X.2014.919141

Rispoli, M., O’Reilly, M., Lang, R., Sigafoos, J., Mulloy, A., Aguilar, J., \& Singer, G. (2011). Effects of language of implementation on functional analysis outcomes. Journal of Behavioral Education, 20(4), 224-232. doi: 10.1007/s10864-011-9128-7.

Rivera, C. J., Wood, C. L., \& Spooner, F. (2012). Comparative effects of Spanish and English vocabulary instruction for English language learners with moderate intellectual disability. Multiple Voices for Ethnically Diverse Exceptional Learners, 13(1), 42-55.

Rohena, E. I., Jitendra, A. K., \& Browder, D. M. (2002). Comparison of the effects of Spanish and English constant time delay instruction on sight word reading by Hispanic learners with mental retardation. Journal of Special Education, 36(3), 169-184. 
Romero, C. (2015). An investigation of alternative language services (ALS) received by English language learners (ELLS) identified with a disability (Unpublished doctoral dissertation). University of New Mexico, Albuquerque New Mexico.

Samson, J. F., \& Lesaux, N. K. (2009). Language-minority learners in special education: Rates and predictors of identification for services. Journal of Learning Disabilities, 42(2), 148162. doi: $10.1177 / 0022219408326221$

Smith, P. (2007). Have we made any progress? Including students with intellectual disabilities in regular education classrooms. Intellectual and Developmental Disabilities, 45(5), 297309.

Spooner, F., Rivera, C. J., Browder, D. M., Baker, J. N., \& Salas, S. (2009). Teaching emergent literacy skills using cultural contextual story-based lessons. Research and Practice for Persons and Severe Disabilities, 34(3-4), 102-112.

Sullivan, A. L. (2011). Disproportionality in special education identification and placement of English language learners. Exceptional Children, 77(3), 317- 334.

Thomas, W. P., \& Collier, V. P. (2012). Dual language education for a transformed world. Albuquerque, NM: Dual Language Education of New Mexico/Fuente Press.

Thordardottir, E. (2010). Towards evidence-based practice in language intervention for bilingual children. Journal of Communication Disorders, 43, 523 - 537.

United Nations, the Ad Hoc Committee on a Comprehensive and Integral International Convention on Protection and Promotion of the Rights and Dignity of Persons with Disabilities. (2006). Convention on the rights of persons with disabilities. Retrieved from http://www.un.org/disabilities/convention/conventionfull.shtml. 
Vallar, G., \& Papagno, C. (1993). Preserved vocabulary acquisition in Down's syndrome: The role of phonological short term memory. Cortex, 29(3), 467-483.

Verhoeven, L. \& Vermeer, A. (2006). Literacy achievement of children with intellectual disabilities and differing linguistic background. Journal of Intellectual Disability Research, 50(10), 725-738.

Woll, B., \& Grove, N. (1996). On language deficits and modality in children with Down syndrome: A case study of twins bilingual in BSL and English. Journal of Deaf Studies and Deaf Education, 1(4), 271-278.

Yu, B. (2013). Issues in bilingualism and heritage language maintenance: Perspectives of minority-language mothers of children with Autism Spectrum Disorders. American Journal of Speech-Language Pathology, 22, 10-24. 


\section{Job description}

\section{Appendix 1: Interview Questions}

a) To begin, please describe what your job entails. That is, what are your main duties and responsibilities?

2. Access to language programs

a) What programs or services are available [in your workplace/in the agencies you oversee] to help children learn another language or become bilingual?

b) Do children with DD participate in the [refer to the programs described by the participant in $2 a$ e.g., immersion programs, heritage language programs, ESL, foreign language classes, bilingual...] programs or services you just described?

1. [If yes] how often do they participate (e.g., every time they ask)?

2. When they participate, could you describe how fully they participate?

c) What, if anything, prevents or limits a child with DD from participating in the [heritage language/second language/immersion/bilingual...] programs or services you have described?

d) What, if anything, facilitates or supports a child with DD to fully participate in the programs or services you have described?

e) If a child with DD is admitted to [heritage language/second language/immersion/bilingual...] programs or services do they have access to the full range of services and programs available for children with special needs?

f) In your opinion, are the services and supports that are available for children with DD to become or stay bilingual adequate? If not, what improvements could be made? [Probe for the range of services identified in $2 a]$.

3. Special education, assessment, treatment of children with DD

a) Please briefly overview the educational, assessment, and/or treatment services or programs are available [in your workplace/in the agencies you oversee] to support children with DD?

b) What modifications or accommodations, if any, are made in [your workplace/the agencies you oversee] when educating, assessing, or treating a bilingual child with DD?

c) For children who do participate in the [programs described for DD], what factors (if any) are important in their success in becoming/staying bilingual? What factors hinder or limit their success?

d) Are the services/supports for children with DD to become/stay bilingual adequate? If not, what improvements could be made?

\section{$\underline{4 .}$ Alternative Communication Systems}

We've been focusing primarily on children who use spoken language as their primary mode of communication. What about children who use an alternative form of communication such as a picture board, gestures/signs, or an electronic device? Please discuss any issues you feel are relevant regarding bilingualism and a child who uses an alternative communication system.

Follow-up question: Do you think children who use alternative communication systems should have the opportunity to use their systems in more than one language? Why or why not? $\underline{\text { 5. Literacy }}$

We also have not explicitly talked about reading and writing. Please discuss any issues 
you think are relevant about children with DD learning to read and write in two languages. 6. Decision-making

a) Resources are always an issue in service delivery. Choices have to be made. To what extent do you feel [your workplace / the agencies you oversee] should prioritize bilingualism for children with DD?

b) What do you think would be the best way for [your workplace / the agencies you oversee] to support bilingualism for children with DD?

\section{Demographic Questions}

1. Age

2. What are your professional credentials (i.e., teacher, special education teacher, speech-

language pathologist, psychologist, etc.)?

3a. What is your job title?

3b. How long have you worked at this job?

4a. If you are retired or recently changed jobs, what was your last job title?

4b. How long did you work at that job?

4c. When did you stop working at that job?

Languages you speak and use

5a. Are you bilingual or multilingual? Yes/No

- If yes, which languages do you know?

$5 \mathrm{~b}$. Of the languages that you identified in 5a:

- Which did you learn as mother tongue(s)/first language(s)?

- Which did you learn as second or additional languages, after you acquired your mother tongue(s)/first language(s)?

The next questions ask about how you use language in your daily life. By the word 'use', we mean any of the following: speaking, listening and understanding, reading, and writing. 5c. Do you use two or more languages in the course of your daily life at home? Yes/No $5 d$. Do you use two or more languages in the course of your daily life at work? Yes/No

5e. Do you use two or more languages in the course of your daily life in your community (e.g., in stores, at community events, in clubs)? Yes/No 
Table 1. Demographic information by site location.

\begin{tabular}{|c|c|c|c|c|c|c|}
\hline & $\begin{array}{c}\text { BC } \\
\mathrm{N}=15\end{array}$ & $\begin{array}{c}\mathbf{Q C} \\
\mathrm{N}=9\end{array}$ & $\begin{array}{c}\text { NS } \\
\mathrm{N}=15\end{array}$ & $\begin{array}{c}\text { NM } \\
\mathrm{N}=14\end{array}$ & $\begin{array}{c}\text { UK } \\
\mathrm{N}=14\end{array}$ & $\begin{array}{c}\text { NL } \\
N=12\end{array}$ \\
\hline \multicolumn{7}{|l|}{ Primary Language of Workplace ${ }^{1}$} \\
\hline English & 14 & 5 & 9 & 13 & 14 & 1 \\
\hline French & 0 & 3 & 3 & 0 & 0 & 0 \\
\hline English \& French & 0 & 1 & 2 & 0 & 0 & 0 \\
\hline English \& Spanish & 0 & 0 & 0 & 1 & 0 & 0 \\
\hline Dutch & 0 & 0 & 0 & 0 & 0 & 10 \\
\hline Dutch \& Dutch Sign Language & 0 & 0 & 0 & 0 & 0 & 1 \\
\hline \multicolumn{7}{|l|}{ Type of Workplace $^{2}$} \\
\hline School & 4 & 3 & 4 & 6 & 0 & 2 \\
\hline School Board & 2 & 5 & 2 & 0 & 0 & 0 \\
\hline Government/Local Authority & 1 & 1 & 3 & 0 & 1 & 3 \\
\hline Intervention Centre & 4 & 0 & 3 & 0 & 0 & 0 \\
\hline Health Care/Clinic/Hospital & 0 & 0 & 2 & 0 & 3 & 0 \\
\hline Other & 3 & 0 & 0 & 8 & 4 & 1 \\
\hline Special Education (NL only) & & & & & & 6 \\
\hline \multicolumn{7}{|l|}{ Job Title } \\
\hline Program president/director & 7 & 0 & 3 & 8 & 1 & 2 \\
\hline Coordinator/team leader & 2 & 0 & 4 & 0 & 2 & 3 \\
\hline Consultant/specialist & 2 & 3 & 3 & 0 & 2 & 0 \\
\hline Policy maker & 2 & 4 & 3 & 4 & 0 & 4 \\
\hline Speech-language pathologist & 2 & 1 & 0 & 1 & 4 & 1 \\
\hline $\begin{array}{l}\text { Other (principals, teachers, } \\
\text { psychologists, pediatricians, and } \\
\text { researchers) }\end{array}$ & 0 & 1 & 2 & 1 & 5 & 2 \\
\hline Multiple Languages Used in Workplace ${ }^{3}$ & 2 & 7 & 7 & 8 & 3 & 6 \\
\hline
\end{tabular}

